This is a post print version of:

\author{
Shtaya, M. J. Y, T. C. Marcel, J. C. Sillero, R. E. Niks and D. Rubiales, \\ 2006
}

Identification of QTLs for powdery mildew and scald resistance in barley

Euphytica, 151:421-429

DOI 10.1007/s10681-006-9172-x 


\title{
Identification of QTLs for powdery mildew and scald resistance in barley
}

\author{
Shtaya, M. J. Y' ${ }^{1}$, T. C. Marcel $^{3}$, J. C. Sillero², R. E. Niks ${ }^{3}$ and D. Rubiales ${ }^{1}$ \\ ${ }^{1}$ Institute of Sustainable Agriculture, CSIC, Apdo. 4084, 14080 Córdoba, Spain \\ 2 CIFA, Alameda Del Obispo, IFAPA, Apdo. 3092, 14080 Córdoba, Spain \\ ${ }^{3}$ Laboratory of Plant Breeding, P. O. Box 386, 6700 Wageningen, the Netherlands
}

\begin{abstract}
A population of 103 recombinant inbred lines (RILs, $\mathrm{F}_{9}$-derived lines) developed from the two-row spring barley cross L94x'Vada' was evaluated under field conditions for resistance against powdery mildew (Blumeria graminis f.sp. hordei) and scald (Rhynchosporium secalis). Apart from the major resistance gene mlo on chromosome $4(4 \mathrm{H})$, two QTLs (Rbgql and $R b g q 2)$ for resistance against powdery mildew were detected on chromosomes $3(3 \mathrm{H})$ and $7(5 \mathrm{H})$, respectively. Rbgql has not been reported before, and does not map to a chromosome region where a major gene for powdery mildew has been reported. $R b g q 2$, which appeared in one year's trial, may be allelic to the $M l(T R)$ major gene. Four QTLs (Rrsq1, Rrsq2, Rrsq3 and $\operatorname{Rrsq4}$ ) for resistance against scald were detected on chromosomes $3(3 \mathrm{H}), 4(4 \mathrm{H})$ and 6 $(6 \mathrm{H})$. All four mapped to places where QTLs for scald resistance have been reported before in different populations. The confidence interval of Rrsq2 contained $m l-o$. It cannot be excluded that $\operatorname{Rrsq} 2$ is due to a pleiotropic effect of $m l-o$ on scald.
\end{abstract}

Keywords Barley, Blumeria graminis f.sp. hordei, partial resistance, QTL mapping, Rhynchosporium secalis.

\section{Introduction}

Powdery mildew (Blumeria graminis f.sp. hordei) and scald (Rhynchosporium secalis) are two of the most economically important foliar diseases of barley (Hordeum vulgare) (Shipton et al. 1974; Balkema-Boomstra \& Mastebroek 1995). Powdery mildew and scald can be controlled by the use of fungicides, but the use of genetic resistance is the most effective, economic and environmentally sound way to control these diseases. Twenty three different major genes for resistance against powdery mildew and fifteen major genes for resistance against scald have been reported so far (Chelkowski et al. 2003; Genger et al. 2005). 
Almost all these genes give a hypersensitive type of resistance and had a short effective life as new virulent races of the pathogens have evolved that overcame the corresponding resistance, with the exception of the mlo resistance gene (Hovmøller et al. 2000; Xi et al. 2002). This short life of resistance has caused breeders to look for other types of resistance such as partial resistance (PR) which appears to be more durable and race-non-specific (Niks et al. 2000). PR has been defined as a resistance causing a reduced rate of epidemic development despite a high, susceptible, infection type (Parlevliet 1975).

In the barley - Puccinia hordei pathosystem, this PR inherits polygenically (Qi et al. 1998b). Polygenically inherited PR has also been identified against powdery mildew and scald (Hautea et al. 1987; Kari \& Griffiths 1997). The relation between QTLs for PR and major genes for hypersensitivity is still a matter of debate. QTLs for PR may be allelic variants of R-genes or may govern a separate system of defence on its own. Where PR is based on a different mechanism than post-haustorial hypersensitivity, and the genes do not map to loci known to carry also major genes for hypersensitive resistance, it has been suggested that PR has a different evolutionary origin than major genic hypersensitivity resistance (Qi et al. 1998b).

Where minor genes for PR co-localise to loci for major-genic resistance (e.g. in Backes et al. 2003), the minor genes for PR may be allelic versions of major genes for hypersensitivity, or be defeated alleles of such major genes. Evidence for the latter has been found in rice resistance to rice bacterial blight (Xanthomonas oryzae pv. oryzae) (Li et al., 2001)

The use of molecular markers has facilitated the construction of extensive linkage maps in barley (Graner et al. 1991; Qi et al. 1998a). By the availability of such dense linkage maps, individual gene loci (Quantitative trait loci, QTL) for disease resistance have been identified and mapped in different genetic backgrounds (Jahoor et al. 2004; Hayes et al. 2001). QTL mapping is a highly effective means for studying genetically complex disease resistance such as quantitatively inherited resistance. Not only we can determine and compare the loci involved in a resistance, but also the relative size of their effect on the epidemic, the parent contributing the allele for resistance and the effectiveness of each locus in various plant development stages or against various pathogen isolates (Qi et al. 1998b, 1999).

The objective of this study was the identification of genes for resistance to powdery mildew (Blumeria graminis f.sp. hordei) and scald (Rhynchosporium secalis) in a population of 103 recombinant inbred lines (RILs) derived from a cross between L94 x 'Vada' and 
comparing the map positions of QTLs for resistance against powdery mildew and scald with those of major resistance genes reported in literature.

\section{Materials and methods}

\section{Plant material}

The resistance tests were performed on a population of 103 recombinant inbred lines (RILs, $\mathrm{F}_{9}$-derived lines) developed from the two-row spring barley cross L94 x 'Vada'. L94 is an Ethiopian landrace with black and naked seeds, is very susceptible to leaf rust (Qi et al. 1998b) and resistant to powdery mildew (Jørgensen 1992) and resistant to scald (D. Rubiales, unpublished data). The L94 line is one of the Ethiopian lines known to carry the mlo gene for resistance to powdery mildew (Jørgensen 1992). 'Vada' is a West-European cultivar with white and covered seeds that carries a high level of PR to leaf rust (Parlevliet 1975). It is known to possess the MlLa major gene for powdery mildew resistance (Giese et al. 1993), and it appears to have a low level of PR to scald (Rowling \& Jones 1976). Since virulence to MlLa occurs commonly in Europe (Hovmøller et al. 2000), 'Vada' can readily be infected in the field. The 103 RILs and their two parents were used in all tests. The same mapping population had been used to map QTLs for PR to barley leaf rust (Puccinia hordei) (Qi et al. 1998b; 1999) and leaf stripe (Pyrenophora graminea) (Arru et al. 2002).

\section{Disease assessments}

Field testing was performed at CIFA experimental farm at Córdoba, Spain, over the course of three years $(2002,2003$ and 2004). RILs were sown in a randomised complete block design in three replicates. Each RIL was represented by 25-30 seeds in a single row of one meter long per replicate. No artificial inoculation was performed since mildew and scald incidence is usually high at this location. RILs alternated with single rows of 'Vada' as reference and as spreader for the two pathogens. Disease severity was estimated (one, two or three times per season, depending on pathogen and year) as the percentage of leaf area covered by powdery mildew colonies or scald lesions.

To verify the mlo-carrying RILs, as determined by Qi et al. (1998a), a detached leaf test was performed. About 15 seeds per RIL were sown in $7 \times 7 \times 11 \mathrm{~cm}$ pots. A central leaf segment of about $50 \mathrm{~mm}$ per seedling was excised 11 days after sowing (first leaf fully expanded), and placed, adaxial surface up, in a square petri dish $(12 \times 12 \mathrm{~cm})$ filled with $0.6 \%$ agar and 125 ppm Benzimidazole. During both growing seasons, a sample of powdery 
mildew was collected from the field of Córdoba and was maintained on a set of seedlings of various cultivars of which 'Vada' appeared to be the most susceptible. Two days before the inoculation of the RILs, 'Vada' stock plants were shaken to discard old spores. Fresh spores were blown from the infected 'Vada' stock, over the leaf segments in a settling tower. Every inoculation comprised 10 petri dishes together in the tower. In each petri dish, 4 segments per RIL (24 segments in total) were laid out. A glass slide was placed among the petri dishes to monitor inoculum density, which was adjusted to give approximately 20 conidia $\mathrm{mm}^{-2}$. After inoculation, petri dishes were transferred to a growth chamber at $18-20{ }^{\circ} \mathrm{C}$ and incubated in darkness for $12 \mathrm{~h}$. Then they were transferred to a growth chamber with fluorescent light (12 $\mathrm{h}$ light / $12 \mathrm{~h}$ dark) and $18-20{ }^{\circ} \mathrm{C}$ (Edwards 1993). Infection type (IT) was recorded five days after inoculation, following the 0-4 scale of Moseman (1965). This scale was extended by the score 0(4) for the presence of few colonies, which is characteristic for resistance due to mlo (Czembor 2001). To separate the mlo holding RILs from the RILs with high level of PR, infection frequency was recorded by counting the number of powdery mildew colonies in one square $\mathrm{cm}$.

During the experiment period, we determined the virulence factors present in the powdery mildew population by exposing a set of 17 of the most commonly used differentials of Pallas-near-isogenic lines (Hovmøller et al. 2000) to powdery mildew spores collected in the field following the procedure described above.

Powdery mildew severity was scored twice every year. During 2002 no epidemic of powdery mildew developed. For each RIL the average severity over both evaluations was calculated and used for QTL-mapping. Scald severity was estimated once in 2002 and three times at two weeks interval in 2004. During 2003 no epidemic of scald developed. AUDPC (area under disease progress curve) was calculated (Jeger \& Viljanen-Rollinson 2001) and converted to values relative to the AUDPC of the susceptible check ('Vada' $=100 \%$ ). This relative AUDPC was used for QTL-mapping.

\section{Genotyping and map construction}

A dense marker map from the cross L94 x 'Vada' was available (Qi et al. 1998a), which contains 561 AFLP markers, three morphological markers, one disease resistance gene and one STS marker. To this map we added 25 SSR and CAPS markers. We recalculated the map and extracted a skeletal map of 244 markers to be used in QTL-mapping. The total map length was $1118 \mathrm{cM}$. 


\section{Statistical analysis}

The ANOVA was calculated by using the PROC GLM in SAS programme (SAS Institute 1988). The wide-sense heritability $\left(\mathrm{h}^{2}\right)$ for the level of infection by two pathogens was estimated. A computer software package, MAPQTL version 5.0 modified from version 3.0 (Van Ooijen \& Maliepaard 1996), was used for interval mapping. In the region of the putative QTLs, the markers with the highest LOD values (peak markers) were used as cofactors for running a multiple-QTL mapping programme, the MQM method (Jansen \& Stam 1994). When LOD values of some markers on other regions reached the significance level, the MQM was repeated by adding those new 'peak markers' as co-factors until a stable LOD profile was reached. The restricted MQM method (rMQM) was used to determine the confidence interval for the detected QTLs. A LOD value of 3 was chosen as threshold value for declaring a QTL (Qi et al. 1998b). MQM results were used to determine the values of the LOD, phenotypic variation and additive effect of QTLs.

\section{Results}

\section{Powdery mildew}

Few changes in the virulence composition of the powdery mildew population were detected during the two years' experiments. The powdery mildew population collected in 2003 was avirulent to Mla3, Mla6, Mla13, Mla14, MlRu3, Mlat and mlo. The mildew population collected in 2004 was avirulent to Mla3, Mla13, MlRu3 and mlo. Therefore in both years virulence to the $M l L a$ resistance gene was present in the mildew population. As expected mlo was effective to both years' mildew populations

In the seedling test, the 103 RILs segregated for infection type. 52 RILs showed infection type 0 or 0(4) and 51 RILs showed infection type 3 or 4 . The resistant RILs (IT 0 , $0(4)$ ) showed an infection frequency of 0 to 12 colonies per $\mathrm{cm}^{2}$ and the susceptible RILs (IT 3-4) showed an infection frequency of 76 to 133 colonies per $\mathrm{cm}^{2}$, without intermediate cases. This observed ratio of 52:51 (resistant: susceptible) does not deviate significantly from the 1:1 ratio suggesting a single gene for resistance. We mapped the resistance gene at $89.5 \mathrm{cM}$ from the tip of the short arm of Chromosome $4(4 \mathrm{H})$, indicating, as expected, that this gene is the mlo resistance locus.

In the field the RILs showed the same observed segregating ratio. For QTL mapping only the 51 RILs with IT 3-4 (Mlo allele) were used. They segregated quantitatively in severity of infection. Fig. 1A-B shows the frequency distribution of the 51 RILs during the 
two years. Disease severity was higher in 2003 than in 2004 (population mean 7\% and 4\% respectively). L94 and 'Vada' had disease severities of $0 \%$ and 14\% (2003) and of $0 \%$ and $3 \%$ (2004) respectively with RILs ranging from $0 \%$ to $16 \%$ in both years. The heritability was about 0.4 in both years.

Figure 1A-D. Frequency distribution of phenotypes for powdery mildew (51 RILs $\mathrm{F}_{9}$ ) and scald (103 RILs $\mathrm{F}_{9}$ ) derived from a cross L94 x 'Vada'. A: powdery mildew severity in the field during 2003. B: powdery mildew severity in the field during 2004. C: scald severity in the field during 2002. D: scald relative AUDPC in the field during 2004. The values indicated on the $\mathrm{x}$-axis are the lower limit of each class.

A

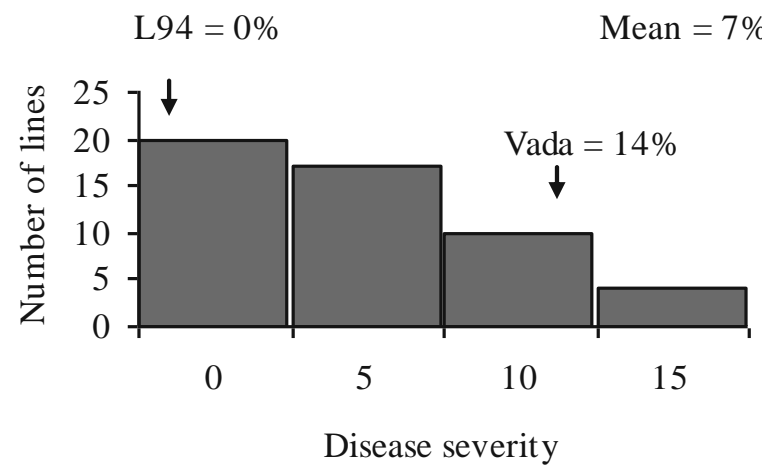

C

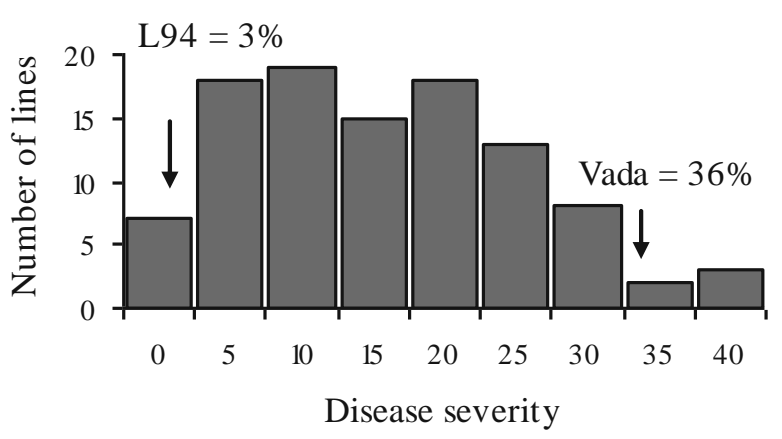

B

$$
\mathrm{L} 94=0 \%
$$$$
\mathrm{Vada}=3 \%
$$

Mean $=4 \%$

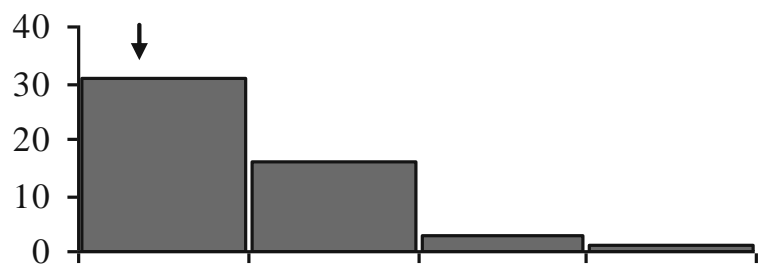

0

5

10

15

Disease severity

D

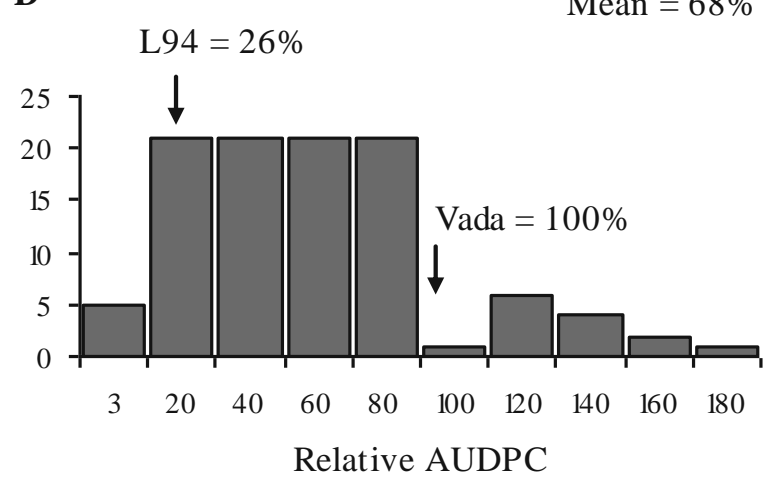

In 2003 no obvious transgressive segregation was detected in this population since none of the RILs showed disease severity significantly higher than 'Vada' (Duncan, $P \leq$ 0.05). In 2004 a strong transgressive segregation towards susceptibility was found since many RILs showed disease severity significantly higher than in the most susceptible parent 'Vada' (Duncan, $P \leq 0.05$ ).

In total two QTLs for PR to powdery mildew were identified and were tentatively

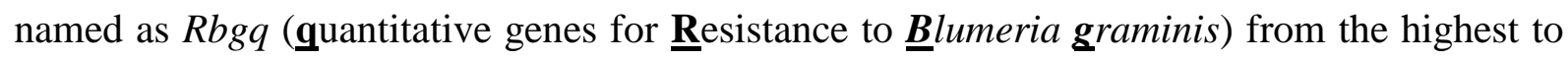
the lowest LOD score (Table 1 and Fig. 2). One QTL (Rbgql) was detected for both years' data on chromosome 3 (3H) (Table 1) with the resistance allele being contributed by L94. 
Table 1. Summary of QTLs for partial resistance to powdery mildew identified in the cross L94 x 'Vada'.

\begin{tabular}{|c|c|c|c|c|c|c|c|c|c|}
\hline \multirow[b]{2}{*}{ QTL } & \multirow[b]{2}{*}{ Chromosome } & \multicolumn{4}{|c|}{2003} & \multicolumn{4}{|c|}{2004} \\
\hline & & $\overline{\mathrm{cM}}$ & LOD & $\operatorname{Exp} \%^{a}$ & Add $^{\mathrm{b}}$ & $\overline{\mathrm{cM}}$ & LOD & $\operatorname{Exp} \%^{\mathrm{a}}$ & Add $^{b}$ \\
\hline$R b g q 1$ & $3(3 \mathrm{H})$ & 53 & 7.4 & 32.7 & -2.7 & 64.7 & 3.4 & 24.1 & -1.9 \\
\hline Rbgqq2 & $7(5 \mathrm{H})$ & 142.9 & 3.9 & 14.5 & 1.8 & 142.9 & 0.1 & 0.6 & 0.3 \\
\hline Total $^{\mathrm{c}}$ & & & & 47.2 & -0.9 & & & 24.1 & -1.9 \\
\hline
\end{tabular}

${ }^{a}$ The proportion of the explained phenotypic variation

${ }^{\mathrm{b}}$ Effect of alleles from L94

${ }^{\mathrm{c}}$ Sum of the values of the significant QTLs (Bold font)

This QTL caused the strongest effect, explaining $32.7 \%$ and $24.1 \%$ of the total phenotypic variation for 2003 and 2004 respectively. One more QTL was detected in the 2003 experiment only and was designated Rbgq2, located on the long arm of chromosome $7(5 \mathrm{H})$ with the resistance allele from 'Vada'. This QTL explained $14.5 \%$ of the phenotypic variation. The total phenotypic variation explained by the QTLs detected in the population was $47.2 \%$ in 2003 and $24.1 \%$ in 2004.

\section{Scald}

For the 2002 trial, disease severity based on one severity reading was used as parameter for level of infection, while for 2004 AUDPC was calculated and used as parameter for level of infection. During 2002, the disease severity of the 103 RILs ranged from 0 to $43 \%$ and the AUDPC converted to a value relative to the AUDPC on 'Vada', ranged from 3\% to 200\% in 2004 (Figs. 1C and D). L94 and 'Vada' had disease severities of 3\% and 36\% in 2002 and during 2004 the actual disease severity for L94 and 'Vada' at the final evaluation date was $12 \%$ and $46 \%$ respectively. The heritability $\left(\mathrm{h}^{2}\right)$ was 0.58 and 0.65 for 2002 and 2004 respectively. No transgressive segregation was detected in 2002 but it was in 2004 (Figs. 1C and D).

Table 2. Summary of QTLs for partial resistance to scald (Rhynchosporium secalis) identified in the cross L94 $\mathrm{x}$ 'Vada'.

\begin{tabular}{|c|c|c|c|c|c|c|c|c|c|}
\hline \multirow[b]{2}{*}{ QTL } & \multirow[b]{2}{*}{ Chromosome } & \multicolumn{4}{|c|}{2002} & \multicolumn{4}{|c|}{2004} \\
\hline & & $\overline{c M}$ & LOD & $\operatorname{Exp} \%^{\mathrm{a}}$ & Add $^{\mathrm{b}}$ & $\overline{\mathrm{cM}}$ & LOD & $\operatorname{Exp} \%^{a}$ & $\operatorname{Add}^{\mathrm{b}}$ \\
\hline Rrsql & $6(6 \mathrm{H})$ & 7.9 & 3.8 & 11.2 & -3.4 & 9.9 & 4.4 & 13.0 & -14.5 \\
\hline $\operatorname{Rrsq} 2$ & $4(4 \mathrm{H})$ & 88.6 & 3.3 & 9.7 & -3.2 & 88.9 & 4.6 & 12.7 & -14.1 \\
\hline $\operatorname{Rrsq} 3$ & $6(6 \mathrm{H})$ & 59.2 & 3.8 & 12.2 & 3.9 & 59.2 & 0.1 & 0.3 & -2.3 \\
\hline Rrsq4 & $3(3 \mathrm{H})$ & 58.1 & 3.1 & 9.1 & -3.1 & 58.1 & 2.7 & 7.2 & -10.7 \\
\hline Total $^{c}$ & & & & 42.2 & -5.8 & & & 25.7 & -28.5 \\
\hline
\end{tabular}

\footnotetext{
${ }^{a}$ The proportion of the explained phenotypic variation

${ }^{\mathrm{b}}$ Effect of alleles from L94

${ }^{c}$ Sum of the values of the significant QTLs (Bold font)
} 
All 103 RILs were used for QTL-mapping to scald. In total four QTLs for PR were identified. They were tentatively named as $\operatorname{Rrsq}$ (quantitative genes for $\underline{\mathbf{R}}$ esistance to $\underline{\boldsymbol{R}}$ hynchosporium secalis) from the highest to the lowest LOD score (Table 2 and Fig. 2). Two QTLs (Rrsq1 and $\operatorname{Rrsq2}$ ) were detected both years in nearly the same confidence intervals on chromosomes $6(6 \mathrm{H})$ and $4(4 \mathrm{H})$ respectively. Each QTL explained about $10 \%$ of the phenotypic variation (Table 2). One QTL (Rrsq3 on chromosome 6 (6H)) was detected only in the 2002 experiment. Another QTL (Rrsq4 on chromosome 3 (3H)) contributed significantly in 2002 but just below the significance level (LOD 2.7) in 2004. The total phenotypic variation explained by the QTLs detected in the population was $42.2 \%$ in 2002 and $25.7 \%$ in 2004 . The confidence interval of the Rrsq2 resistance allele included the mlo-recessive allele for powdery mildew resistance (Figure 2). The resistance alleles of $\operatorname{Rrsq1}$, Rrsq2 and $\operatorname{Rrsq} 4$ were from L94 while the resistance allele of Rrsq3 was from 'Vada'.

\section{Discussion}

Many research groups have now reported QTLs for PR in barley populations (e.g. Heun 1992; Thomas et al. 1995; Qi et al. 1998b; Arru et al. 2002). Most reported QTLs are listed in Hayes et al. (2001) and Jahoor et al. (2004). The paucity of common markers between studies and the differences in germplasm and environment makes the comparison of the location of QTLs between studies difficult. For that reason Kleinhofs \& Graner (2001) implemented the BIN-map, in which the barley map is subdivided into segments, BINs, of about $10 \mathrm{cM}$ each. In the present study the BIN map will be used to compare the detected QTLs with QTLs and major genes detected in other mapping populations.

The resistance of our population parents against powdery mildew was assumed to be based on the mlo and MlLa resistance genes (Giese et al. 1993; Qi et al. 1998a). The mlo resistance gene was mapped on the long arm of chromosome $4(4 \mathrm{H})$ about $3 \mathrm{cM}$ proximal from the mlo position previously reported by Qi et al. (1998b). This $3 \mathrm{cM}$ difference is due to recalculation of the map after addition of the 25 extra markers. The MlLa resistance gene has been reported to be located on the distal part of the long arm of chromosome $2(2 \mathrm{H})$ (Giese et al. 1993). The Pallas-MlLa near-isogenic line in our differential set indicated that in both years the powdery mildew population was virulent to MlLa. In agreement with this, we did not find any effect of the MlLa locus on the severity in the QTL-mapping, not even in 2004 when 'Vada' was almost completely resistant. 
Figure 2. Location of QTLs for resistance to powdery mildew and scald on the skeletal map of barley, based on 51 RILs for powdery mildew and 103 RILs for scald, from a cross L94 x 'Vada'. Chromosomes were oriented with the short arms to the top. Kosambi's mapping function was used. Names of QTLs are to the left of each QTL. Boxes left to the chromosome bars are the QTLs for scald in 2002 and 2004, and boxes inside the chromosome bars are the QTLs for powdery mildew in 2003 and 2004. Length of bars corresponds to two LOD support intervals (from peak) based on the results of the rMQM method. To the left of the chromosome bars all reported loci of race specific resistance genes against powdery mildew $(M l)$ and scald $(R r s)$ are indicated.
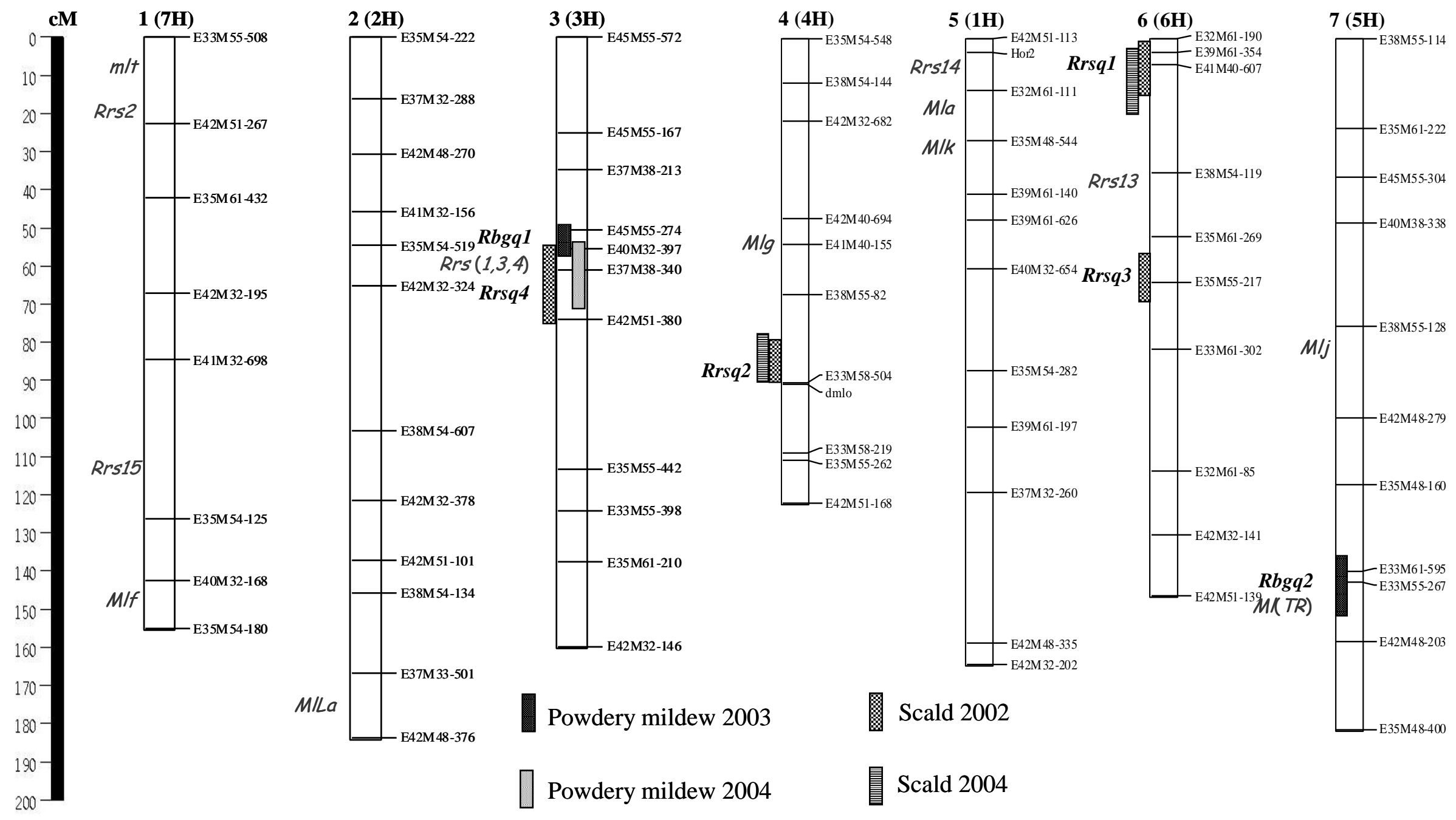

Scald 2004 
Two QTLs for resistance against powdery mildew were identified. One of these, Rbgq1, that we detected in both years on chromosome $3(3 \mathrm{H})$, has not been reported before. The fact that Rbgql was detected in both years lends confidence to the reliability of this QTL. The other QTL, Rbgq2, mapped at $143 \mathrm{cM}$ from the tip of the short arm on chromosome 7 $(5 \mathrm{H})$, seems to coincide with a QTL reported by Spaner et al. (1998) in the $14^{\text {th }}$ BIN and by Saghai Maroof et al. (1994) at a similar position. It is possible that some other QTLs for powdery mildew resistance with smaller effects were not identified due to the very small population size (51 RILs) and the low level of infection and, as a consequence, the modest contrast in infection severity between the RILs. The occurrence of transgressive segregation in 2004 would imply a role for resistance genes from both parents. This we found in the 2003 trial but not in the 2004 trial. At present we have no explanation for this.

There is no indication that QTL Rbgql detected on chromosome $3(3 \mathrm{H})$ is co-located or allelic to a major gene for powdery mildew resistance since no such major gene has been mapped on chromosome 3 (3H) (Chelkowski et al. 2003; Jahoor et al. 2004). QTL Rbgq2 for powdery mildew resistance on chromosome $7(5 \mathrm{H})$ may co-locate and be allelic to the major gene for powdery mildew resistance designated as $M l(T R)$ in the Harrington x TR306 cross (Falak et al. 1999). This gene caused infection type 1-2 in the study of Falak et al. (1999). Since there is no $M l(T R)$-Pallas near isogenic line available, virulence against $M l(T R)$ has not been quantified in surveys in Europe (Hovmøller et al. 2000). Jørgensen (cited by Falak et al. 1999) reported virulence to this gene in European powdery mildew. Since $M l(T R)$ had been discovered recently in a Canadian breeding line, it is not likely that 'Vada' carries this $M l(T R)$ allele.

From our results we can conclude that the resistance against powdery mildew segregating in our population is based on mlo and on at least two QTLs located on chromosome $3(3 \mathrm{H})$ and $7(5 \mathrm{H})$.

In the present study, four QTLs for PR against $R$. secalis were detected on chromosome $3(3 \mathrm{H}), 4(4 \mathrm{H})$ and $6(6 \mathrm{H})$. Both the resistant and the susceptible parents (L94 and 'Vada' respectively) contributed alleles for resistance against scald. QTL Rrsq1 on the distal part of the short arm of chromosome $6(6 \mathrm{H})$ may correspond to a QTL at a similar mapping position in Alexis x Regatta cross (Jensen et al. 2002). QTL Rrsq2 on chromosome 4 (4H) may correspond to the QTL for scald resistance detected in the Harrington $x$ TR306 cross with the resistance allele contributed by TR306 (Spaner et al. 1998). QTL Rrsq3 detected on the proximal part of the short arm of chromosome $6(6 \mathrm{H})$ may coincide with a QTL detected in two mapping populations. It occurred in the 'Igri' $\mathrm{x}$ 'Danilo' cross (Backes 
et al. 1995), and in the Harrington x TR306 cross (Spaner et al. 1998). QTL Rrsq4 on chromosome $3(3 \mathrm{H})$ coincides with a QTL detected in three mapping populations. It occurred in the Blenheim x E224/3 cross with the resistance allele contributed by E224/3 (Thomas et al. 1995), in the Harrington $x$ TR306 cross with the resistance allele contributed by Harrington (Spaner et al. 1998), and in the Ingrid x Abyssinian cross with the resistance allele contributed by Abyssinian (Grønnerød et al. 2002). QTL Rrsq4 may be the same as the QTL detected in the Ingrid x Abyssinian since both Abyssinian and L94, also known as Abyssinian 1102, are of Ethiopian origin (Jørgensen 1992). In conclusion, all the QTLs for PR against scald detected in the present L94 x 'Vada' cross are supported by previously mapped QTLs in various barley populations.

Major genes for resistance against scald have been mapped to barley chromosomes 1 $(7 \mathrm{H}), 3(3 \mathrm{H}), 4(4 \mathrm{H}), 5(1 \mathrm{H})$ and $6(6 \mathrm{H})$ (Schweizer et al. 1995; Graner \& Tekauz 1996; Garvin et al. 2000; Genger et al. 2005). We found two QTLs (Rrsq1 and Rrsq3) for scald resistance on chromosome $6(6 \mathrm{H})$ in the $1^{\text {st }}$ and $5^{\text {th }}$ BIN respectively and it is unlikely that any one of these two QTLs co-locate with the Rrs13 major gene for scald resistance which is reported to occur in the $3^{\text {rd }}$ BIN of chromosome 3 (3H) (Abbott et al. 1995). QTL Rrsq2 detected on chromosome $4(4 \mathrm{H})$ does not coincide with any major gene(s) for resistance against scald, but, interestingly, its confidence interval contained the locus mlo for resistance against powdery mildew. Further studies should be made to determine whether the recessive mlo locus and the QTL allele for scald resistance are genetically linked or due to a pleiotropic effect of mlo. QTL Rrsq4 detected near the centromere of chromosome $3(3 \mathrm{H})$ may be allelic to the complex locus, $\operatorname{Rh}(\operatorname{Rrs} 1)-\operatorname{Rrs} 3-\operatorname{Rrs} 4$, for scald resistance (Graner \& Tekauz 1996).

Some QTLs identified in this study (Rbgq2 and Rrsq3) were found only in one out of the two years' trials. This may be due to inconsistent expression of those QTLs, to isolate specificity of those genes or to experimental error.

The present study demonstrated that this population segregated for at least two QTLs for powdery mildew resistance and four QTLs for scald resistance. At least Rbgq1, Rrsq1, $\operatorname{Rrsq} 2$ and Rrsq 3 do probably not co-localise with major genes for hypersensitive resistance. It would be interesting to determine their mode of action to the pathogen in order to decide whether they may constitute a separate class of genes for PR, as reported in the barley leaf rust system (Qi et al. 1998b).

\section{Acknowledgments}


The authors gratefully acknowledge the Spanish Agency for International Cooperation (AECI), CICYT project AGF99-1036-CO1 and the European Cereal Atlas Foundation (ECAF) fellowship for financial support.

\section{References}

Abbott, D. C., E. S. Lagudah \& A. H. D. Brown, 1995. Identification of RFLPs flanking a scald resistance gene on barley chromosome 6. J Hered 86: 152-153.

Arru, L., R. E. Niks, P. Lindhout, G. Valé, E. Francia \& N. Pecchioni, 2002. Genomic regions determining resistance to leaf stripe (Pyrenophora graminea) in barley. Genome 45: 460466.

Backes, G., A. Graner, B. Foroughi-Wehr, G. Fischbeck, W. Wenzel \& A. Jahoor, 1995. Localization of quantitative trait loci (QTL) for agronomic important characters by the use of a RFLP map in barley (Hordeum vulgare L.). Theor Appl Genet 90: 294-302.

Backes, G., L. H. Madsen, H. Jaiser, J. Stougaard, M. Herz, V. Mohler \& A. Jahoor, 2003. Localisation of genes for resistance against Blumeria graminis f.sp. hordei and Puccinia graminis in a cross between a barley cultivar and a wild barley (Hordeum vulgare ssp. spontaneum) line. Theor Appl Genet 106: 353-362.

Balkema-Boomstra, A. G \& H. D. Mastebroek, 1995. Effect of powdery mildew (Erysiphe graminis f.sp. hordei) on photosynthesis and grain yield of partially resistance genotypes of spring barley (Hordeum vulgare L.). Plant Breed 114: 126-130.

Chelkowski, J., M. Tyrka \& A. Sobkiewicz, 2003. Resistance genes in barley (Hordeum vulgare L.) and their identification with molecular markers. J Appl Genet 44: 291-309.

Czembor, J. H., 2001. Sources of resistance to powdery mildew (Blumeria graminis f. sp. hordei) in Moroccan barley land races. Can J Plant Pathol 23: 260-269

Edwards, H. H., 1993. Light affects the formation and development of primary haustoria of Erysiphe graminis hordei in leaf epidermal cells of Hordeum vulgare. Phys Mol Plant Pathol 42: 299-308.

Falak, I., D. E. Falk, N. A. Tinker \& D. E. Mather, 1999. Resistance to powdery mildew in a doubled haploid barley population and its association with market loci. Euphytica 107: $185-192$. 
Garvin, D. F., A. H. D. Brown, H. Raman \& B. J. Read, 2000. Genetic mapping of the barley Rrs14 scald resistance gene with RFLP, isozyme and seed storage protein markers. Plant Breed 119: 193-196.

Genger, R. K., K. Nesbitt, A. H. D. Brown, D. C. Abbott \& J. J. Burdon, 2005. A novel barley scald resistance gene: genetic mapping of the Rrs15 scald resistance gene derived from wild barley, Hordeum vulgare ssp. spontaneum. Plant Breed 124: 137-141.

Giese, H., A. G. Holm-Jensen, H. P. Jensen \& J. Jensen, 1993. Localization of the Laevigatum powdery mildew resistance gene to barley chromosome 2 by the use of RFLP markers. Theor Appl Genet 85: 897-900.

Graner, A., A. Jahoor, J. Schondelmaier, H. Siedler, K. Pillen, G. Fischbeck, G. Wenzel \& R. G. Herrmann, 1991. Construction of an RFLP map of barley. Theor Appl Genet 83: 250256.

Graner, A., \& A. Tekauz, 1996. RFLP mapping in barley of a dominant gene conferring resistance to scald (Rhynchosporium secalis). Theor Appl Genet 93: 421-425.

Grønnerød, S., A. G. Marøy, J. MacKey, A. Takauz, G. A Penner \& A. Bjørnstad, 2002. Genetic analysis of resistance to barley scald (Rhynchosporium secalis) in the Ethiopian line ‘Abyssinian' (CI668). Euphytica 126: 235-250.

Hautea, R. A., W. R. Coffman, M. E. Sorrells \& G. C. Bergstrom, 1987. Inheritance of partial resistance to powdery mildew in spring wheat. Theor Appl Genet 73: 609-615.

Hayes, P. M., A. Castro, L. Marquez-Cedillo, A. Corey, C. Henson , B. Jones, J. Kling, D. Mather, I. Matus, C. Rossi \& K. Sato, 2001. A summary of published barley QTL reports. http://barleyworld.org/northamericanbarley/qtlsummary.php.

Heun, M., 1992. Mapping quantitative powdery mildew resistance of barley using a restriction fragment length polymorphism map. Genome 35: 1019-1025.

Hovmøller, M. S., V. Caffier, M. Jalli, O. Andersen, G. Besenhofer, J. H. Czembor, A. Dreiseitl, F. Felsenstein, A. Fleck, F. Feinrics, R. Jonsson, E. Limpert, P. Mercer, S. Plesnik, I. Rashal, H. Skinnes, S. Slater \& O. Vronska, 2000. The European barley powdery mildew virulence survey and disease nursery 1993-1999. Agronomie 20: 729743.

Jahoor, A., L. Eriksen \& G. Backes, 2004. QTLs and genes for disease resistance in barley and wheat. In: Cereal Genomics, P. K. Gupta \& R. K. Varshney (eds), Kluwer Academic Publisher, the Netherlands, pp. 199-251.

Jansen, R. C. \& P. Stam, 1994. High resolution of quantitative traits into multiple loci via interval mapping. Genetics 136: 1447-145. 
Jeger, M. J. \& S. L. H. Viljanen-Rollinson, 2001. The use of the area under the diseaseprogress curve (AUDPC) to assess quantitative disease resistance in crop cultivars. Theor Appl Genet 102: 32-40.

Jensen, J., G. Backes, H. Skinnes \& H. Giese, 2002. Quantitative trait loci for scald resistance in barley localized by a non-interval mapping procedure. Plant Breed 121: 124-128.

Jørgensen, J. H., 1992. Discovery, characterization and exploitation of Mlo powdery mildew resistance in barley. Euphytica 63: 141-152.

Kari, A. G. \& E. Griffiths, 1997. Inheritance of components of partial resistance of barley to Rhynchosporium secalis with particular reference to race specificity. Ann Appl Biol 131: 43-62.

Kleinhofs, A \& A. Graner. 2001. DNA-Based Markers in Plants. $2^{\text {nd }}$ Edition pp187-199.

Parlevliet, J. E., 1975. Partial resistance of barley to leaf rust, Puccinia hordei. I. Effect of cultivar and development stage on latent period. Euphytica 24: 21-27.

Li, Z. -K., A. Sanchez, E. Angeles, S. Singh, J. Domingo, N. Huang \& G. S. Khush, 2001. Are the dominant and recessive plant disease resistance genes similar?: A case study of rice $\mathrm{R}$ genes and Xanthomonas oryzae pv. oryzae races. Genetics 159: 757-765.

Moseman, J. G. 1965. Genetic studies with cultures of Erysiphe graminis f. sp. hordei virulent on Hordeum spontaneum. Trans. Brit. Mycol. Soc. 48: 479 - 489.

Niks, R. E., U. Walther, H. Jaiser, F. Martínez, D. Rubiales, O. Anderson, K. Flath, P. Gymer, F. Heinrichs, R. Jonsson, L. Kuntze, M. Rasmussen \& E. Richter. 2000. Resistance against barley leaf rust Puccinia hordei in West-European spring barley germplasm. Agronomie 20: $769-782$.

Qi, X., P. Stam \& P. Lindhout, 1998a. Use of locus specific AFLP markers to construct a high density molecular map in barley. Theor Appl Genet 96: 376-384.

Qi, X., R. E. Niks, P. Stam \& P. Lindhout, 1998b. Identification of QTLs for partial resistance to leaf rust (Puccinia hordei) in barley. Theor Appl Genet 96: 1205-1215.

Qi, X., G. Jiang, W. Chen, R.E. Niks, P. Stam \& P. Lindhout, 1999. Isolate-specific QTLs for partial resistance to Puccinia hordei in barley. Theor Appl Genet 99: 877 - 884.

Rowling, R. H. D. \& D. G. Jones, 1976. The reaction of three spring barley varieties exposed to epidemics of Rhynchosporium secalis of varying intensity and duration. J Agr Sci 87: $643-647$.

Saghai Maroof, M. A, Q. Zhang \& R. M. Biyashev, 1994. Molecular marker analysis of powdery mildew resistance in barley. Theor Appl Genet 88: 733-740.

SAS Institute, 1988. SAS user guide: Statistics. SAS Institute, Cary, N.C. 
Schweizer, G. F., M. Baumer, G. Daniel, H. Rugel \& M. S. Röder, 1995. RFLP markers linked to scald (Rhynchosporium secalis) resistance gene Rh2 in barley. Theor Appl Genet 90: 920-924.

Shipton, W. A., W. J. R. Boyd \& S. M. Ali, 1974. Scald of barley. Rev Plant Path 53: 839861.

Spaner, D., L. P. Shugar, T. M. Choo. I. Falak, K. G. Briggs. W. G. Legge, D. E. Falk, S. E. Ullrich, N. A. Tinker, B. J. Steffenson \& D. E. Mather, 1998. Mapping of disease resistance loci in barley on the basis of visual assessment of naturally occurring symptoms. Crop Sci 38: 843-850.

Thomas, W. T. B., W. Powell, R. Waugh, K. J. Chalmers, U. M. Barua, P. Jack, V. Lea, B. P. Forster, J. S. Swanston, R. P. Ellis, P. R. Hanson \& R. C. M. Lance, 1995. Detection of quantitative trait loci for agronomic, yield, grain and disease characters in spring barley (Hordeum vulgare L.). Theor Appl Genet 91: 1037-1047.

Van Ooijen, J. W. \& C. Maliepaard, 1996. MAPQTL ${ }^{(\mathrm{TM})}$ version 3.0: software for the calculation of QTL positions on genetic maps. CPRO-DLO, Wageningen.

Xi, K., T. K. Turkington, J. H. Helm \& C. Bos, 2002. Pathogenic variation of Rhynchosporium secalis in Alberta. Can J Plant Pathol 24: 176-163. 